Table 1. Mean (SE) PAAP score, ${ }^{a}$ SF-36v2Q7 score ${ }^{b}$ and SF-36v2 BP $^{c}$ at baseline through M6(FAS) in RA and PsA csDMARD-IR or TNFi-IR population, and SF-36v2Q7 score, ${ }^{\text {b }}$ and SF-36v2 $\mathrm{BP}^{\mathrm{c}}$ at baseline and $\mathrm{W} 12$ (FAS) in the AS population

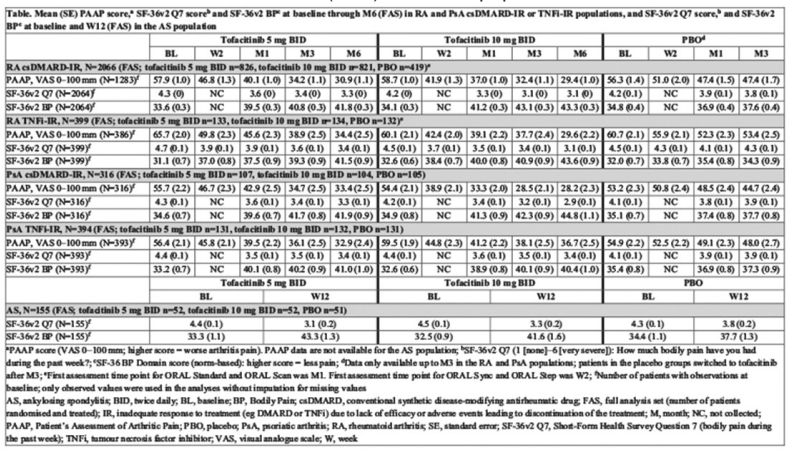

Conclusions: Treatment with tofacitinib is associated with a rapid improvement and sustained reduction of pain in pts with RA and PSA who are csDMARD-IR or TNFi-IR, and in pts with AS.

Acknowledgements: Study sponsored by Pfizer Inc. Medical writing support was provided by P Scutt of CMC and funded by Pfizer Inc.

Disclosure of Interest: A. Ogdie Grant/research support from: Novartis, Consultant for: Novartis, Pfizer Inc, Takeda, K. de Vlam Consultant for: Eli Lilly, Pfizer Inc, I. Mclnnes Grant/research support from: Celgene, Janssen, Novartis, Pfizer Inc, Roche, UCB, Consultant for: AbbVie, Celgene, Janssen, Novartis, Pfizer Inc, Roche, UCB, P. Mease Grant/research support from: AbbVie, Amgen, BristolMyers Squibb, Celgene, Janssen, Lilly, Novartis, Pfizer Inc, Sun, UCB, Consultant for: AbbVie, Amgen, Bristol-Myers Squibb, Celgene, Janssen, Lilly, Novartis, Pfizer Inc, Sun, UCB, Speakers bureau: AbbVie, Amgen, Bristol-Myers Squibb, Celgene, Genentech, Janssen, Novartis, Pfizer Inc, UCB, P. Baer Consultant for: AbbVie, Amgen, Janssen, Johnson and Johnson, Lilly, Novartis, Paladin, Pfizer Inc, Sanofi-Genzyme, Takeda, Speakers bureau: Amgen, Janssen, Lifelass, Pfizer Inc, T. Lukic Shareholder of: Pfizer Inc, Employee of: Pfizer Inc, K. Kwok Shareholder of: Pfizer Inc, Employee of: Pfizer Inc, C. Wang Shareholder of: Pfizer Inc, Employee of: Pfizer Inc, M.-A. Hsu Shareholder of: Pfizer Inc, Employee of: Pfizer Inc, A. Maniccia Shareholder of: Pfizer Inc, Employee of: Pfizer Inc

DOI: 10.1136/annrheumdis-2018-eular.3247

\section{SAT0222 CLINICAL RISK STRATIFICATION FOR HYDROXYCHLOROQUINE PRESCRIBING IN A LARGE URBAN DISTRICT GENERAL HOSPITAL}

A. Saravanan 1 , T. Ahmed $1 .{ }^{1}$ Rheumatology Department, Croydon University Hospital, LONDON, United Kingdom

Background: New 2017 British Society of Rheumatology guidelines have recommended baseline formal ophthalmic examination, ideally including objective retinal assessment for example using optical coherence tomography, within 1 year of commencing an antimalarial drug. While the feasibility and costing of this recommendation is being assessed, we audited the current risk assessment for hydroxychloroquine prescriptions (HCQ) against the American College of Ophthalmology (ACO) guidelines for HCQ published in 2016. Table 1 shows the clinical criteria for assessment.

Methods: We identified all prescriptions of HCQ documented on the electronic patient records (EPR) from January to September 2017 by the Rheumatology department of Croydon University Hospital. This generated 237 records of which 114 were new prescriptions and 117 were continuation prescriptions. 8 records were excluded due to inadequate patient compliance. Cumulative doses were estimated from dates in the EPR going back to 2013

Results: New patient records were assessed for compliance with the ACO guidelines. Patients were assessed for kidney function, pre-existing renal disease, pre- existing eye disease. $74.6 \%$ patients were counselled regarding side effects and were advised to have optician retinal screening and $3.5 \%$ who had pre-existing eye disease were referred to ophthalmologists. $50.0 \%$ of patients had their weight documented prior to prescription. There was no documentation of dose calculated by weight. The commonest indication for HCQ were Systemic Lupus Erythmatosis, Inflammatory Arthritis and Sjogren's Syndrome. 13.2 \% discontinued HCQ due to side effects. The commonest side effects were diarrhoea, dizziness, rashes, and mood swings.

Long- term patient records were assessed for cumulative dose of HCQ estimated from documentation. The average cumulative dose for these patients was with a maximum of $810,000 \mathrm{mg}$ and a minimum of $49,600 \mathrm{mg}$. Overall, $3.0 \%$ percentage of patients did not have cumulative doses calculated due to documented compliance issues and $64.0 \%$ of patients had tightly monitored renal function.
Table 1 Clinical criteria for HCQ risk assessment based on American College of Ophthalmology guidelines (2016)

\begin{tabular}{|c|c|}
\hline \multicolumn{2}{|c|}{$\begin{array}{c}\text { TABLE 1. } \\
\text { Clinical criteria for HCQ risk assessment based on American College of } \\
\text { Ophthalmology guidelines (2016) }\end{array}$} \\
\hline \begin{tabular}{|l|} 
Factors Assessed \\
\end{tabular} & Explanation \\
\hline $\begin{array}{l}\text { Cumulative dose } \\
<5 \mathrm{mg} / \mathrm{kg} \text { daily } \\
\text { dose for } 5 \text { years }\end{array}$ & $\begin{array}{l}\text { Guidelines recommend a daily dose of }<5 \mathrm{mg} / \mathrm{kg} \text {. Any higher can incrementally } \\
\text { increase the risk of retinopathy }\end{array}$ \\
\hline Duration of Use & $\begin{array}{l}\text { Decades of use can increase the risk, even in patients on the recommended daily } \\
\text { dose. }\end{array}$ \\
\hline $\begin{array}{l}\text { Renal Disease } \\
\text { Screening }\end{array}$ & $\begin{array}{l}\text { HCQ is cleared by the kidneys, any drop in GFR can increase circulating drug } \\
\text { doses therefore increase risk of toxicity. }\end{array}$ \\
\hline $\begin{array}{l}\text { Retinal Baseline } \\
\text { Screening }\end{array}$ & $\begin{array}{l}\text { Retinal screening is recommended for all patients to monitor the Retinal } \\
\text { Pigment Epithelium damage therefore preserve central vision }\end{array}$ \\
\hline Tamoxifen Use & $\begin{array}{l}\text { Use of tamoxifen alongside HCQ can increase the risk of toxicity approximately } \\
\text { 5-fold. }\end{array}$ \\
\hline $\begin{array}{l}\text { Pre-existing } \\
\text { Retinal OR } \\
\text { Macular disease }\end{array}$ & Eye sight can worsen on initiating $\mathrm{HCQ}$. \\
\hline
\end{tabular}

Conclusions: $50 \%$ of patients had weight documented prior to prescription and this was not used to determine dosage. The majority of patients were well informed regarding side-effects of $\mathrm{HCQ}$, had tightly monitored renal function and advised to have baseline retinal screening.

Disclosure of Interest: None declared

DOI: 10.1136/annrheumdis-2018-eular.1209

\section{SAT0223 PREDICTIVE FACTORS OF EARLY FAILURE TO FIRST LINE TREATMENT WITH METHOTREXATE IN PATIENTS WITH RHEUMATOID ARTHRITIS. RESULTS FROM THE GISEA REGISTRY.}

A. Manfredi ${ }^{1}$ on behalf of GISEA, M. Sebastiani ${ }^{1}$, F. lannone ${ }^{2}$, E. Gremese ${ }^{3}$, A. Bortoluzzi ${ }^{4}$, E. G. Favalli ${ }^{5}$, R. Gorla ${ }^{6}$, F. Salaffi $^{7}$, E. Fusaro ${ }^{8}$, R. Foti $^{9}$ L. Cantarini ${ }^{10}$, R. Caporali ${ }^{11}$, A. Cauli ${ }^{12}$, S. Alivernini ${ }^{3}$, F. P. Cantatore ${ }^{13}$, A. Carletto ${ }^{14}$, F. Conti $^{15}$, S. D'Angelo ${ }^{16}$, O. Epis $^{17}$, R. Ramonda ${ }^{18}$, A. Marchesoni $^{5}$, F. Atzeni ${ }^{19}$, P. Sarzi-Puttini ${ }^{20}$, G. Ferraccioli ${ }^{3}$, G. Lapadula ${ }^{2}$ on behalf of GISEA (Gruppo Italiano Studio Early Arthritis). ${ }^{1}$ Rheumatology Unit, University of Modena and Reggio Emilia, Modena, ${ }^{2}$ Rheumatology Unit, University of Bari, Bari, ${ }^{3}$ Rheumatology Unit, Catholic University of Sacred Heart, Rome, ${ }^{4}$ Rheumatology Unit, University of Ferrara, Ferrara, ${ }^{5}$ Rheumatology Unit, Gaetano Pini Institute Milano, ${ }^{6}$ Rheumatology Unit, Spedali Civili di Brescia, Brescia, ${ }^{7}$ Rheumatology Unit, Università Politecnica delle Marche, Jesi, ${ }^{8}$ Rheumatology Unit, AOU Città della Salute e della Scienza, Torino, ${ }^{9}$ Rheumatology Unit, Policlinico Vittorio Emanuele, Catania, ${ }^{10}$ Rheumatology Unit, University of Siena, Siena, ${ }^{11}$ Rheumatology Unit, University of Pavia, Pavia, ${ }^{12}$ Rheumatology Unit, University of Cagliari, Cagliari, ${ }^{13}$ Rheumatology Unit, University of Foggia, Foggia, ${ }^{14}$ Rheumatology Unit, University of Verona, Verona, ${ }^{15}$ Rheumatology Unit, University La Sapienza, Rome, ${ }^{16}$ Rheumatology Unit, Azienda Ospedaliera Regionale "San Carlo", Potenza, ${ }^{17}$ Rheumatology Unit, Niguarda Hospital, Milano, ${ }^{18}$ Rheumatology Unit, University of Padova, Padova, ${ }^{19}$ Rheumatology Unit, University of Messina, Messina, ${ }^{20}$ Rheumatology Unit, Sacco Hospital, Milano, Italy

Background: Methotrexate (MTX) is generally recommended as first-line treatment of rheumatoid arthritis (RA). Despite its efficacy is well established, a percentage of patients fails the treatment. Few studies investigated the causes of early discontinuation of MTX; a two-year retention rate of about $66 \%$ is described for RA patients with lower age and longer disease duration as independent predictors for discontinuation.

Objectives: Aim of this study was to detect possible predictive factors for early discontinuation of MTX prescribed as first line treatment in RA patients enrolled in the GISEA (Italian Group for the Study of Early Arthritis) registry.

Methods: RA patients who began MTX as first line treatment were included in the study. For all patients age, sex, disease duration, smoking status, the intake of glucocorticoids, clinical and serological data, comorbidities and extra-articular manifestations were collected.

Results: We analyzed 612 RA patients (females/males 477/132, mean age $55.73 \pm 14.5$ years; mean DAS28 $5.35 \pm 1.5$ ); rheumatoid factor (RF) was positive in $64.9 \%$, anti-citrullinated peptide antibodies (ACPA) in 42.7\%. Comorbidities were observed in $17.5 \%$ of patients, while extra-articular RA manifestations were recorded in $1.5 \% ; 68.3 \%$ of subjects taken low doses of steroids.

One hundred and forty-nine (24.3\%) patients discontinued MTX during the first year (for inefficacy in 66/149 (44.3\%) patients, adverse events in 51/149 (34.2\%), and other reasons in 32/149 (21.5). At univariate analysis early discontinuation of MTX was associated to a lower mean age $(p=0.041)$ and a higher mean tender 